\title{
Assessment of pregnancy outcome with low molecular weight heparin therapy: a retrospective, single centre observational study
}

\author{
Ankita Singh, Madhuri Alwani*, Nutan Yadav, Priyam Padia
}

Department of Obstetrics and Gynecology, Sri Aurobindo Medical College and PG Institute, Indore, India

Received: 05 January 2018

Accepted: 03 March 2018

\section{*Correspondence:}

Dr. Madhuri Alwani,

E-mail: drmadhuri_2007@rediffmail.com

Copyright: ( $)$ the author(s), publisher and licensee Medip Academy. This is an open-access article distributed under the terms of the Creative Commons Attribution Non-Commercial License, which permits unrestricted non-commercial use, distribution, and reproduction in any medium, provided the original work is properly cited.

\begin{abstract}
Background: The objective of this study was to determine the outcomes of Low Molecular Weight Heparin Therapy (LMWH) given for various indications during pregnancy.

Methods: In this context, a detailed retrospective analysis of all the patients who received LMWH for various indications over a period of two years from October 2015 to November 2017 at a single center, Sri Aurobindo Medical College and PG institute in Indore was performed.

Results: Total 100 patients were studied, included over the period of 2 years for various indications for which Enoxaparin ( $1 \mathrm{mg} / \mathrm{kg}$ body weight OD/BD subcutaneously) was used. The indications were valvular heart disease with valve replacement and atrial fibrillation (54.0\%), chronic deep vein thrombosis (DVT) (13.0\%), thrombophilias (9.0\%), recurrent pregnancy loses $(21.0 \%)$ and prophylaxis for deep vein thrombosis $(3.0 \%)$ in overall patients. Abortion was seen in $8.0 \%$ patients; fetal growth restriction in $13 \%$ patients; and oligohydramnios, preeclampsia, gestational hypertension, placenta previa, abruptio placentae, postpartum hemorrhage patients and Stillbirth occurred in $4.0 \%$ patients. No thromboembolic event was noted in any of the patients. None of the patients had any documented thrombocytopenia or clinical fracture.

Conclusions: Low Molecular Weight Heparin Therapy (LMWH) used amongst pregnant women with various indications for anticoagulation therapy was associated with successful pregnancy outcome in the vast majority of cases. Further multicenter prospective studies and international registries of pregnant women on LMWH are necessary to broaden our knowledge in optimizing the care of women who require anticoagulation during pregnancy.
\end{abstract}

Keywords: Low molecular weight heparin therapy, Pregnancy, Thromboembolism

\section{INTRODUCTION}

There are various indications for anticoagulation treatment during pregnancy. Pregnancy and the postpartum period are especially thrombogenic. ${ }^{1}$ Low molecular weight heparin (LMWH) is now the most commonly used anticoagulant for prophylaxis and treatment of venous thromboembolism in postpartum period and pregnancy. ${ }^{2,3} \mathrm{LMWH}$ for the prevention or treatment of thromboembolism has certain advantages over unfractionated heparin (UHF) including greater bioavailability, more reliable pharmacokinetics, fewer bleeding complications and lower instances of osteoporosis and thrombocytopenia. ${ }^{4,5}$. The reliable pharmacokinetics of LMWHs and their long half-life, resulting in the need for less frequent injections than UFH, makes them attractive for practical use in the nine months of pregnancy. Widespread use over the last ten years has shown that LMWHs are safer than UFH in pregnancy. Owing to their predictable dose-response, LMWH does not require routine laboratory monitoring or dose adjustments in the majority of nonpregnant patients, 
thus allowing for more convenient regimens. ${ }^{6}$ As they do not cross the placenta and are safe in breast feeding, LMWH has gained widespread use in pregnancy. ${ }^{7-10}$ Systematic reviews suggest that enoxaparin therapy appears to be safe and efficacious when used in pregnant women. ${ }^{11-13}$ There is, however, poor consensus and wide disparity of views among experts with regard to the appropriate dose for the varying indications, the duration of treatment, and whether and how LMWH should be monitored because of the lack of an evidence base. These areas of uncertainty reflect the fact that clinical practice has grown largely through the publication of small observational studies, personal experience and anecdote. There are no such studies from the Indian population; good clinical data are urgently required. Thus, this is a retrospective single centre observational analysis to evaluate safety and efficacy of LMWH given during pregnancy for the various indications.

\section{METHODS}

\section{Study design}

We retrospectively evaluated the medical records of all the patients who received therapeutic LMWH doses during pregnancy for the various indications over period of 2 years from October 2015 to November 2017 was performed. The study included 100 patients. All enrolled patients delivered in our hospital but the majority of them had their regular examinations and treatment provided by their physicians in primary or secondary health care centers. The characteristics of the patients, dosages, frequency, duration and indication of LMWH were recorded. Maternal complications in the form of hemorrhagic or thromboembolic event, thrombocytopenia, and other obstetric complications, if any, were assessed. The obstetric and fetal outcomes were recorded in terms of the period of gestation at delivery, live birth/stillbirth/abortions, birth weight, mode of delivery, Apgar score, and other fetal or neonatal complications, if any.

\section{Statistical Analysis}

All analyses were performed in SPSS Version 21.0. Descriptive statistics (including mean, standard deviation, range, frequency, and percent) were calculated to characterize the study. The chi-square test or Fisher's exact test was used, as appropriate, to evaluate the association between maternal complications, infant complications, dosing adjustment, type of pregnancy and adverse pregnancy outcomes. All p-values are two-sided with statistical significance evaluated at the 0.05 levels. sonography.

\section{RESULTS}

A total of 100 women were recruited during the study period. The mean age of study patients was $32.4 \pm 5$ years, (range 21-43). The mean height was $1.59 \pm 0.11$ meter (range1.30-1.68). The mean body mass index was 20.1 \pm 5.3 (range 17-32). The obstetric history was gravidity $3.1 \pm 1.4$, parity $1.3 \pm 0.99$, abortions $5 \pm 0.00$ and live birth $2 \pm 0.00$ (range $0-8$ ). Duration of therapy was $8.9 \pm 5.2$ days (range 1-31) (Table 1 ).

Table 1: Basic characteristics of the study population.

\begin{tabular}{|lll|}
\hline Characteristics & Mean \pm SD & Range \\
\hline Age (years) & $32.4 \pm 5$ & $21-43$ \\
\hline Height $($ meter $)$ & $1.59 \pm 0.11$ & $1.30-1.68$ \\
\hline BMI $\left(\mathrm{Kg} / \mathrm{m}^{2}\right)$ & $20.1 \pm 5.3$ & $17-32$ \\
\hline Gravidity & $3.1 \pm 1.4$ & $1-6$ \\
\hline Parity & $1.3 \pm 0.99$ & $0-8$ \\
\hline Abortions & $5.0 \pm 0.00$ & $0-8$ \\
\hline Live Birth & $2.0 \pm 0.00$ & $0-8$ \\
\hline $\begin{array}{l}\text { Duration of therapy } \\
\text { (days) }\end{array}$ & $8.9 \pm 5.2$ & $1-31$ \\
\hline
\end{tabular}

Seventy-two patients received LMWH both in the antepartum as well as the postpartum period, nineteen patients received it in the antepartum period, and eleven patients in the postpartum period. Injection enoxaparin (Clexane) was used in all the patients as it is available in the hospital supply. The dosage of LMWH was $1 \mathrm{mg} / \mathrm{kg}$ body weight once or twice a day, depending on indication. The indications of LMWH therapy was heart disease $(54.0 \%)$, chronic deep vein thrombosis (DVT) (13.0\%), thrombophilias $(9.0 \%)$, recurrent pregnancy loses $(21.0 \%)$ and prophylaxis for deep vein thrombosis $(3.0 \%)$ in overall patients (Figure 2 ).

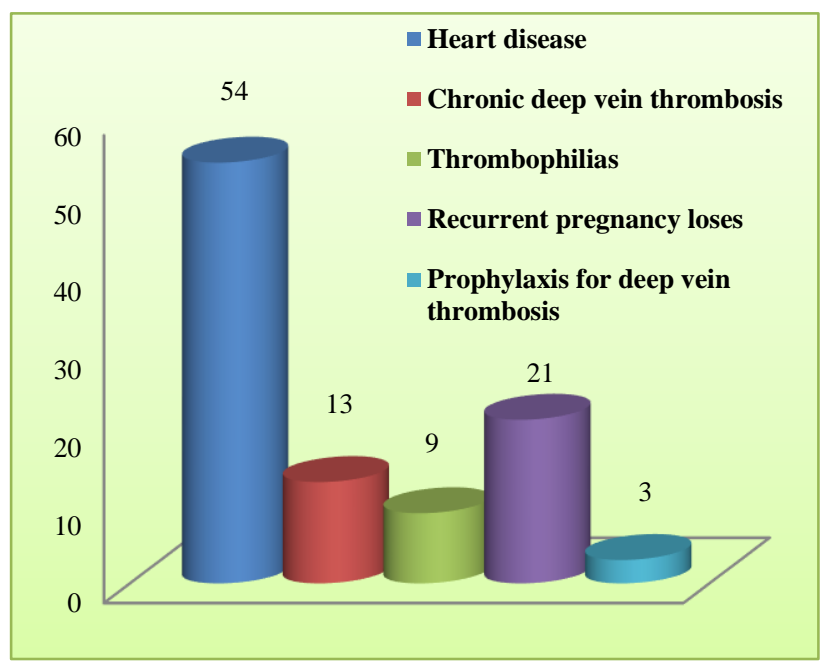

Figure 1: Indications of LMWH therapy in patients.

Patients with heart disease indications represent 54 $(54.0 \%)$, of all patients who required LMWH therapy. The patients with heart disease, chronic deep vein thrombosis (DVT), and prophylaxis of deep vein thrombosis were given enoxaparin $60 \mathrm{mg}$ BD subcutaneously, whereas those with recurrent pregnancy losses were given $40 \mathrm{mg} \mathrm{BD}$. The therapy was commenced at six to eight weeks of gestation and was 
continued till one week postpartum in patients with heart disease, chronic DVT, and thrombophilias and then switched over to warfarin due to the feasibility of oral therapy. The patients with recurrent pregnancy losses without proven thrombophilias were associated LMWH therapy till 36 weeks of gestation. Three post-Cesarean patients were given LMWH therapy for one week in the postpartum period as deep vein thrombosis prophylaxis as these patients were obese (BMI: $>30.9 \mathrm{~kg} / \mathrm{m} 2)$.
The obstetric and fetal outcomes are showed in Table 2 . Among the patients on LMWH therapy, $8.0 \%$ patients had abortions. One patient had missed abortions with no evidence of chorio-decidual bleed on ultrasound.

Two patients had chorio-decidual bleeding followed by a first trimester abortion and another patient had a large $4 \times$ $5 \mathrm{~cm}$ retroplacental hematoma leading to a second trimester abortion at 18 weeks of gestation.

Table 2: Obstetric and fetal outcomes in patients on LMWH therapy for various indications.

\begin{tabular}{|c|c|c|c|c|c|}
\hline & $\begin{array}{l}\text { Heart } \\
\text { Disease } \\
(\mathrm{N}=54)\end{array}$ & $\begin{array}{l}\text { Chronic } \\
\text { DVT }(\mathrm{N}=13)\end{array}$ & $\begin{array}{l}\text { Thrombophilias } \\
(\mathrm{N}=9)\end{array}$ & $\begin{array}{l}\text { Recurrent } \\
\text { pregnancy } \\
\text { Losses }(\mathrm{N}=\mathbf{2 1})\end{array}$ & $\begin{array}{l}\text { DVT } \\
\text { Prophylaxis } \\
(\mathrm{N}=3)\end{array}$ \\
\hline Abortion & $4(7.4 \%)$ & & $2(22.2 \%)$ & $2(9.5 \%)$ & \\
\hline $\begin{array}{l}\text { Intrauterine growth } \\
\text { restriction }\end{array}$ & $5(9.2 \%)$ & & $2(22.2 \%)$ & $4(19.04 \%)$ & \\
\hline Oligohydramnios & & & $2(22.2 \%)$ & & \\
\hline Amniotic band & & $4(30.7 \%)$ & & & \\
\hline Preeclampsia & & & & $2(9.5 \%)$ & \\
\hline Gestational hypertension & & $3(23.0 \%)$ & & & \\
\hline Placenta previa & $2(3.7 \%)$ & & & & \\
\hline Abruptio placentae & & & & $2(9.5 \%)$ & \\
\hline Prematurity & $4(7.4 \%)$ & & $2(22.2 \%)$ & $2(9.5 \%)$ & \\
\hline Vaginal & $42(77.7 \%)$ & $8(61.5 \%)$ & $4(44.4 \%)$ & $14(66.6 \%)$ & \\
\hline LSCS & $8(14.8 \%)$ & $4(30.7 \%)$ & $4(44.4 \%)$ & $2(9.5 \%)$ & $3(100 \%)$ \\
\hline Live birth & $49(90.7 \%)$ & $13(100 \%)$ & $7(77.7 \%)$ & $17(80.9 \%)$ & $3(100 \%)$ \\
\hline still birth & $2(3.7 \%)$ & & & $2(9.5 \%)$ & \\
\hline Postpartum & $2(3.7 \%)$ & & & & \\
\hline Apgar Score at 5 minutes & $2(3.7 \%)$ & & $2(22.2 \%)$ & & \\
\hline NICU & $5(9.2 \%)$ & & $2(22.2 \%)$ & $2(9.5 \%)$ & \\
\hline Respratory (TTN) & $2(3.7 \%)$ & & $2(22.2 \%)$ & & \\
\hline$(\mathrm{TTN})$ & $2(3.7 \%)$ & & & $2(9.5 \%)$ & \\
\hline Neonatal Sepsis & $2(3.7 \%)$ & & & & \\
\hline $\begin{array}{l}\text { Period of gestation at } \\
\text { delivery }\end{array}$ & $36+6.1$ & $38.1+5.3$ & $39.3+4.1$ & $37.5+3.5$ & $38.5+1.8$ \\
\hline Mean birth weight (gm) & $2545+624$ & $2724+684$ & $2716+457$ & $2601+451$ & $3110+357$ \\
\hline
\end{tabular}

Two patients with rheumatic heart disease with thrombosis in the atria had severe fetal growth restriction followed by intrauterine fetal demise. Another patient with history of recurrent pregnancy losses had severe preeclampsia leading to abruptio placentae and fetal demise at 36 weeks. Postpartum hemorrhage was seen in two patients who were managed by oxytocics and uterine massage. No thromboembolic event noted in any of the patients in the study group. None of the patients had any documented thrombocytopenia, clinical fracture, or any allergic skin reactions.

\section{DISCUSSION}

Venous thromboembolism is among the prominent causes of maternal death in developed countries. ${ }^{14-16}$ Modern care has dramatically decreased the risk of maternal death from infection, hypertension and hemorrhage, but rates of death and morbidity from thrombosis have remained stable or increased in current years. ${ }^{17}$ Thrombotic complications risk increase during the period of pregnancy, due to venous stasis and hypercoagulability vascular damage the three elements of Virchow's triad. ${ }^{18}$ Several changes to the maternal coagulation system increase clotting risk. ${ }^{14}$

Present study among pregnant women with a broad variety of indications for LMWH anticoagulation demonstrated a high live birth rate. While side effects were minimal, there were several maternal and infant complications associated with the use of LMWH. 
The physiologic changes of pregnancy alter the metabolism of LMWH, resulting in lower peak levels and a higher rate of clearance, and so a pregnant woman may need higher doses or more frequent dosing. ${ }^{19,20} \mathrm{We}$ used enoxaparin 40-60 mg B.I.D. for 10 patients with thrombophilias and recurrent pregnancy losses. The live birth rate was $77.7 \%$ and stillbirth rate was $4.0 \%$ in these patients. There are various studies assessing the effect of enoxaparin in patients with recurrent pregnancy losses and thrombophilias, but the data are predominantly uncontrolled with small series of patients. Brenner et al described enoxaparin as a safe and effective therapy in prevention of pregnancy loss in women with inherited and acquired thrombophilia. ${ }^{21}$ According to another study, administration of enoxaparin to women with early recurrent fetal loss and impaired fibrinolytic capacity resulted in normalization of impaired fibrinolysis and conception in $80 \%$ and successful live birth in $81 \%$ patients. $^{22}$

Heparin-induced thrombocytopenia is an uncommon but serious adverse effect of unfractionated heparin therapy, caused by heparin-dependent immunoglobulin G (IgG) antibodies that activate platelets via their Fc receptors, potentially precipitating life-threatening arterial or venous thrombosis. Fortunately, heparin-induced thrombocytopenia seems to be very rare in pregnancy. Two recent prospective series evaluating prolonged LMWH use in pregnancy revealed no episodes of this disease. $^{23,24}$ Nonetheless, it is reasonable to measure the platelet count once or twice weekly during the first few weeks of LMWH use and less often thereafter, unless symptoms of heparin-induced thrombocytopenia develop. In pregnant women with heparin induced thrombocytopenia or heparin-related skin reactions, other anticoagulants must be considered. ${ }^{25}$

Immediate anticoagulation is considered the treatment of choice for deep-vein thrombosis (DVT) or pulmonary embolism. Our study demonstrates one regimens of a low-molecular-weight enoxaparin $60 \mathrm{mg}$ b.i.d. in four patients with chronic DVT. Three among them had chronic DVT in the previous pregnancy or postpartum state and one had it after a prolonged surgery and bedridden stage. These patients were started on LMWH at six to eight weeks of gestation and continued in the postpartum stage. The patients had no thrombotic and hemorrhagic complications.

The highest venous thromboembolism risk period is puerperium, which has been informed to be 25 -fold higher than in non-pregnant women and more so in obese women (BMI $\left.30 \mathrm{~kg} / \mathrm{m}^{2}\right) .{ }^{26}$ We used enoxaparin for thromboprophylaxis for seven days in three post-cesarean patients as they were obese (BMI 30.0 to $32.0 \mathrm{~kg} / \mathrm{m}^{2}$ ). LMWH is recommended for thromboprophylaxis in puerperium, at least eight hours after cesarean section. Many study and guidelines recommend that the threshold for prescribing thromboprophylaxis should be lower in the postnatal period than that in the antenatal period. ${ }^{27,28}$
And various recommend that all women who have had cesarean section either elective or emergency, and have one or more additional risk factors (including obesity), should receive thromboprophylaxis with LMWH for seven days. ${ }^{27}$ The obstetric outcomes as observed in this study were similar to prior studies. The stillbirth rate was $4.0 \%$; abortion rate was $8.0 \%$; fetal growth restriction in $13 \%$ patients; and oligohydramnios, preeclampsia, gestational hypertension, placenta previa, abruptio placentae, postpartum hemorrhage patients and stillbirth occurred in $4.0 \%$ patients. Figueiro-Filho et al. used enoxaparin-based intervention in women with thrombophilias and reported a stillbirth rate of $4.0 \%$, abortion rate of $1.2 \%$, live birth rate of $70.2 \%$ and $4.8 \%$ of patients developed preeclampsia. Fetal and neonatal complications as seen in our study were comparable to other studies which consider LMWHs to be safe in pregnancy and lactation. ${ }^{29}$ As per our observation, no incidence of fetal hemorrhage was seen in any of the neonates. LMWH is the preferred agent for anticoagulation in pregnancy as there is no transplacental transfer due to their high molecular weight; hence, the incidence of fetal hemorrhage or teratogenicity is not increased. $^{30}$

The live birth rate in our study was $89.0 \%$ in all patients on enoxaparin therapy in patients with thrombophilia (77.7\%) and recurrent pregnancy losses (80.9\%) receiving this therapy. In another study, live births were reported in $94.7 \%$ of pregnancies in women receiving enoxaparin therapy and in $85.4 \%$ in those receiving LMWH for recurrent pregnancy loss. ${ }^{30}$

This study has important limitations including its retrospective design, the relatively small sample size, and performance in a single hematology clinic practice. It is important to note that our pregnant women were very closely followed in our hematology clinics with the majority of them monitored on a monthly basis. Another major limitation is the heterogeneity of indications for LMWH therapy in the patients included in the study. We present these data as studies regarding LMWH use in pregnant Indian women are lacking. It is not possible to comment upon the exact effect of LMWH therapy on maternal and fetal outcomes for various indications, and hence randomized, controlled trials are indicated.

\section{CONCLUSION}

Prescribing anticoagulants to pregnant women can be difficult and stressful. Fortunately, LMWH is quite safe and efficacious in pregnancy and breast feeding when properly selected, dosed, and monitored. Maternal and fetal concerns always considered at all times, with a careful assessment of the risks and benefits of anticoagulant therapy in each patient. It can be used for various indications like valvular heart disease with valve replacement, atrial fibrillation and thrombus formation, thrombophilias, recurrent pregnancy losses, and prophylaxis or treatment of deep vein thrombosis. Further 
research should help to clarify who should receive thromboprophylaxis, how to prevent adverse pregnancy outcomes in women with various thrombophilias, and how best to treat pregnant women who have a prosthetic heart valve.

\section{ACKNOWLEDGMENTS}

Authors acknowledge to MRD department, SAIMS Indore for providing two-year data.

Funding: No funding sources Conflict of interest: None declared

Ethical approval: The study was approved by the Institutional Ethics Committee

\section{REFERENCES}

1. Lockwood CJ. Heritable coagulopathies in pregnancy. Obstet Gynecol Surv. 1999;54:754-65.

2. Walker MC, Garner PR Keely EJ, Rock GA, Reis MD. Changes in activated protein $\mathrm{C}$ resistance during normal pregnancy. Am J Obstet Gynecol. 1997;177(1):162-9.

3. Thurnau GR, Welsh J, Esmon CT. Functional and immunologic protein $\mathrm{S}$ levels are decreased during pregnancy. Blood. 1986;68(4):881-5.

4. Brenner B. Inherited thrombophilia and pregnancy loss. Best Pract Res Clin Haematol. 2003;16(2):31120.

5. Chighizola CB, Gerosa M, Trespidi L, Di Giacomo A, Rossi F, Acaia B, et al. Update on the current recommendations and outcomes in pregnant women with antiphospolipid syndrome. Expert Rev Clin Immunol. 2014;10(11):1505-17.

6. Ćetković A, Kastratović B, Novaković I. Prospective study of perinatal outcome in pregnancies with primary antiphospholipid syndrome. Vojnosanit Pregl. 2014;71(8):742-5.

7. Kwak-Kim J, Agcaoili MS, Aleta L, Liao A, Ota K, Dambaeva S, et al. Management of women with recurrent pregnancy losses and antiphospolipid antibody syndrome. Am J Reprod Immunol. 2013;69(6):596-607.

8. Alfi rević Z, Roberts D, Nartlew V. How strong is the association between maternal thrombophilia and adverse pregnancy outcome? A systematic review. Eur J Obstet Gynecol Reprod Biol. 2002;101(1):614.

9. Clark P, Walker ID, Langhorne P, Crichton L, Thomson A, Greaves M, et al. Scottish Pregnancy Intervention Study (SPIN) collaborators. SPIN (Scottish Pregnancy Intervention) study: A multicenter, randomized controlled trial of low molecular-weight heparin and low-dose aspirin in women with recurrent miscarriage. Blood. 2010;115(21):4162-7.

10. Kaandorp SP, Goddijn M, van der Post JA, Hutten BA, Verhoeve HR, Hamulyák K, et al., Aspirin plus heparin or aspirin alone in women with recurrent miscarriage. N Engl J Med. 2010;362(17):1586-96.

11. Laskin CA, Spitzer KA, Clark CA, Crowther MR, Ginsberg JS, Hawker GA, et al., Low molecular weight heparin and aspirin for recurrent pregnancy loss: Results from the randomized, controlled HepASA trial. J Rheumatol. 2009;36(2):279-87.

12. Visser J, Ulander VM, Helmerhorst FM, Lampinen $\mathrm{K}$, Morin-Papunen L, Bloemenkamp $\mathrm{KW}$, et al. Thromboprophylaxis for recurrent miscarriage in women with or without thrombophilia. HABENOX: A randomised multicentre trial. Thromb Haemost. 2011;105(2):295-301.

13. Santoro R, Iannaccaro $\mathrm{P}$, Prejano $\mathrm{S}$, Muleo $\mathrm{G}$. Efficacy and safety of the long-termadministration of low-molecular-weight heparins in pregnancy. Blood Coagul Fibrinolysis. 2009;20(4):240-3.

14. Chang J, Elam-Evans LD, Berg CJ, Herndon J, Flowers L, Seed KA et al., Pregnancy-related mortality surveillance-United States, 1991-1999. MMWR Surveill Summ. 2003;52:1-8.

15. Lewis G, Drife JO, Clutton-Brock T., Why Mothers Die: 2000-2002. The Sixth Report of the Confidential Enquiries into Maternal Deaths in the United Kingdom. London: RCOG Press, 2004.

16. Health Canada. Special Report on Maternal Mortality and Severe Morbidity in CanadaEnhanced Surveillance: The Path to Prevention. Ottawa: Minister of Public Works and Government Services Canada, 2004. www.phac-aspc.gc.ca/rhsssg/srmm-rsmm/page1-eng. php.

17. Stein PD, Hull RD, Kayali F, Olson RE, Alshab AK, Meyers FA et al. Venous thromboembolism in pregnancy: 21-year trends. Am J Med. 2004;117:121-5.

18. Greer IA. Thrombosis in pregnancy: maternal and fetal issues. Lancet. 1999;353:1258-65

19. Barbour LA, Oja JL, Schultz LK. A prospective trial that demonstrates that dalteparin requirements increase in pregnancy to maintain therapeutic levels of anticoagulation. Am $\mathbf{J}$ Obstet Gynecol. 2004;191:1024-9.

20. Smith MP, Norris LA, Steer PJ, Savidge GF, Bonnar J. Tinzaparin sodium for thrombosis treatment and prevention during pregnancy. Am J Obstet Gynecol. 2004; 190:495-501.

21. Brenner B, Hoffman R, Blumenfeld Z, et al. Gestational outcome in thrombophilic women with recurrent pregnancy loss treated by enoxaparin. Thromb Haemost. 2000;83(5):693-7.

22. Gris JC, Neveu S, Tailland ML, Courtieu C, Mares $\mathrm{P}$, Schved JF. Use of a low-molecular weight heparin (enoxaparin) or of a phenformin-like substance (moroxydine chloride) in primary early recurrent aborters with an impaired fibrinolytic capacity. Thromb Haemost. 1995;73:362-7.

23. Sanson BJ, Lensing AW, Prins MH, Ginsberg JS, Barkagan ZS, Lavenne-Pardonge E, et al. Safety of low-molecular weight heparin in pregnancy: a 
systematic review. Thromb Haemost. 1999;81:66872

24. Melissari E, Parker CJ, Wilson NV, Monte G, Kanthou C, Pemberton KD, et al., Use of low molecular weight heparin in pregnancy. Thromb Haemost. 1992;68:652-6.

25. Hassell K. The management of patients with heparininduced thrombocytopenia who require anticoagulant therapy. Chest. 2005;127(2):1S-8S.

26. Machado LS. Cesarean section in morbidly obese parturients: practical implications and complications. N Am J Med Sci. 2012;4(1):13-8.

27. Scottish Intercollegiate Guidelines Network (SIGN). Prevention and management of venous thromboembolism. Edinburgh: A National Clinical Guideline; 2010.

28. Royal College of Obstetricians and Gynaecologists. Reducing the risk of thrombosis and embolism during pregnancy and the puerperium. London: Green-Top Guidelines; 2009.
29. Figueiró-Filho EA, Oliveira VM, Breda I, Coelho LR, Ferreira CM. Usefulness of a scoring system on perinatal outcomes in pregnant women with thrombophilia in the effectiveness of an enoxaparinbased intervention. Rev Bras Gynecol Obstet. 2012;34(10):459-65.

30. Greer IA, Nelson-Piercy C. Low-molecular-weight heparins for thromboprophylaxis and treatment of venous thromboembolism in pregnancy: a systematic review of safety and efficacy. Blood. 2005;106:4017.

Cite this article as: Singh A, Alwani M, Yadav N, Padia P. Assessment of pregnancy outcome with low molecular weight heparin therapy: A retrospective, single centre observational study Int J Reprod Contracept Obstet Gynecol 2018;7:1446-51. 